\title{
General hospital presentations of non-fatal hanging over a 28-year period: case-control study
}

Keith Hawton, Helen Bergen, Deborah Casey and Sue Simkin

\begin{abstract}
Summary
Suicide by hanging and self-strangulation ('hanging') has become more common. We studied people who presented to hospital during a 28-year study period after using these methods for non-fatal self-harm. Hanging increased greatly in frequency during this time. The male:female ratio was nearly 3:1. Females were distinguished from males by far higher rates of psychiatric care, personality disorder and previous self-harm. Compared with matched individuals who presented with non-fatal self-poisoning, more of those who
\end{abstract}

used hanging had high suicidal intent, fewer used alcohol in association with the act, and more subsequently died by suicide. They represent an important subgroup of those who self-harm, who require especially careful assessment and follow-up.

\section{Declaration of interest}

None. Funding detailed in Acknowledgements.
Hanging (including self-strangulation; hereafter 'hanging' is used to refer to both methods) is a relatively common suicidal behaviour with a high fatality rate. Its use has increased substantially in the UK and other countries in the past 30 years. Although most frequent in males, rates of suicide by hanging have also doubled in females in this period. ${ }^{1}$ In England and Wales in 2006, $51 \%$ of suicides by males and $34 \%$ by females involved hanging. ${ }^{2}$ We have used a long-standing clinical research database on non-fatal self-harm to investigate: (a) whether the rise in suicides by hanging in the UK is reflected by increases in hospital presentations for non-fatal hanging; (b) the characteristics of individuals who use this method, and especially gender differences; and (c) how individuals who use this method differ in characteristics and outcome from people who present to hospital with self-poisoning, the method used by about $80 \%$ of people who self-harm in England. ${ }^{3}$

\section{Method}

Information on non-fatal self-harm presentations to the general hospital in Oxford between 1978 and 2005 was collected through the Oxford Monitoring System for Attempted Suicide. ${ }^{4}$ Self-harm is defined as intentional self-poisoning or self-injury, irrespective of motivation or degree of suicidal intent.

Data were collected by clinicians from the hospital psychiatric service using special recording forms after they had conducted psychosocial assessments, and by scrutiny of the emergency department and other clinical records by research staff for patients not seen by the service. Information used for this study included age, gender, living circumstances, alcohol use $6 \mathrm{~h}$ before or at the time of the act, previous and current psychiatric care, alcohol and drug misuse, psychiatric and personality disorder, previous self-harm, and suicidal intent (from 1993) using the Beck Suicidal Intent Scale. ${ }^{5,6}$

We selected two self-poisoning controls for each hanging case. They were matched for gender, age, approximate date of presentation, whether or not a psychosocial assessment had been conducted, and residence in Oxfordshire. Information on deaths was available from the Office for National Statistics until the end of 2000 on patients who presented between 1978 and $1997 .{ }^{7}$

Statistical analyses were conducted using Stata version 9 for Windows and conditional logistic regression for comparing matched case-control groups.
Reported denominators for some variables vary because of missing information.

\section{Results}

During the 28-year study period, 166 individuals (121 (72.9\%) males and $45(27.1 \%)$ females) presented to the general hospital after non-fatal hanging. They were involved in 191 episodes: 152 involving hanging and 39 strangulation. They were also involved in 440 other episodes of self-harm.

The numbers of episodes involving hanging increased substantially during the study period, especially between 1992 and 2005: 1978-1984, 16/6139 self-harm episodes (0.26\%); 1985-1991, 12/ 6019 episodes $(0.20 \%)$; 1992-1998, 42/9022 episodes $(0.47 \%)$; $1999-2005,121 / 11403$ episodes $(1.06 \%) \quad\left(\chi^{2}\right.$ for trend $=58.38$, d.f. $=3, P<0.001)$.

Individuals who presented after non-fatal hanging were predominantly single $(94 / 156 ; 60.3 \%)$. Their ages were: $<15$ years, $n=2$ (1.2\%); $15-24$ years, $n=56$ (33.7\%); $25-34$ years, $n=41(24.7 \%)$; $35-54$ years, $n=52(31.3 \%)$; and $55+$ years, $n=15(9.0 \%)$. More females than males were in current psychiatric care $(30 / 44$ (68.2\%) v. 21/104 (20.2\%); $\left.\chi^{2}=31.53, \quad P<0.001\right)$; had received previous psychiatric care (27/31 (87.1\%) v. 31/83 (37.3\%); $\chi^{2}=$ $22.35, P<0.001)$; were currently psychiatric hospital in-patients (11/44 (25\%) v. 6/104 (5.8\%); $\left.\chi^{2}=11.25, P=0.001\right)$; and had previously been psychiatric hospital in-patients (18/31 (58.1\%) v. 16/ $\left.82(19.5 \%) ; \chi^{2}=15.90, P<0.001\right)$. More females had a personality disorder diagnosed (11/16 (68.8\%) v. 7/51 (13.7\%); $\chi^{2}=18.77$, $P<0.001)$ and had a history of self-harm (34/38 (89.5\%) v. 52/98 $\left.(53.1 \%) ; \chi^{2}=15.62, P<0.001\right)$. Suicidal intent scores were similar in males (median 15) and females (median 12; Mann-Whitney $U$, $z=-1.51, P=0.13)$.

Significant findings from univariate analyses (Table 1) indicate that individuals in the hanging (case) group were more likely than those in the self-poisoning (control) group to be living alone or in an institution and to have high scores $(>12)$ on the Suicidal Intent Scale. They were less likely than the controls to have consumed alcohol during the $6 \mathrm{~h}$ before or at the time of selfharm. Multivariate analysis including all significant variables demonstrated that high suicidal intent (odds ratio $(\mathrm{OR})=3.28$, 95\% CI 1.62-6.63) and less frequent use of alcohol in the act ( $\mathrm{OR}=0.34,95 \%$ CI $0.14-0.84)$ independently distinguished the case group from the controls. 


\begin{tabular}{|c|c|c|c|c|}
\hline Independent variables & $\begin{array}{c}\text { Hanging cases } \\
n / N^{\mathrm{b}}(\%)\end{array}$ & $\begin{array}{l}\text { Self-poisoning controls } \\
n / N^{\mathrm{b}}(\%)\end{array}$ & OR $(95 \% \mathrm{Cl})$ & $P$ \\
\hline Married & 32/155 (20.7) & 56/303 (18.5) & $1.19(0.72-1.98)$ & 0.487 \\
\hline Living alone & $62 / 129(48.1)$ & 88/246 (35.8) & $1.78(1.13-2.82)$ & 0.013 \\
\hline Living in an institution & 16/129 (12.4) & $11 / 246$ & $2.85(1.28-6.33)$ & 0.010 \\
\hline Employed & $56 / 143(39.2)$ & $104 / 270(38.5)$ & $1.04(0.68-1.57)$ & 0.899 \\
\hline Alcohol in $6 \mathrm{~h}$ before self-harm & $51 / 122(41.8)$ & $124 / 226(54.9)$ & $0.58(0.37-0.92)$ & 0.020 \\
\hline Alcohol as part of self-harm act & 18/118 (15.3) & 77/213 (36.2) & $0.28(0.15-0.53)$ & $<0.001$ \\
\hline Chronic alcohol misuse & 46/123 (37.4) & 93/223 (41.7) & $0.82(0.52-1.29)$ & 0.85 \\
\hline Drug misuse & 43/138 (31.2) & 59/249 (23.7) & $1.52(0.88-2.61)$ & 0.132 \\
\hline Previous self-harm & $85 / 134(63.4)$ & $157 / 254(60.2)$ & $1.05(0.67-1.65)$ & 0.819 \\
\hline Suicidal Intent Scale $(\text { score }>12)^{c}$ & $45 / 72 \quad(62.5)$ & $36 / 110(32.7)$ & $2.92(1.58-5.40)$ & 0.001 \\
\hline
\end{tabular}

Deaths in the follow-up period occurred in $12 / 52$ (23.1\%) of the case group and $12 / 74\left(16.2 \% ; \chi^{2}=0.54\right.$, not significant $)$ of the controls who presented between 1978 and 1997 and were followed-up until the end of 2000. Death by suicide (including undetermined and accidental poisoning verdicts) was more frequent in the case group than in the controls $(5 / 52,9.6 \% v .0 /$ $74,0.0 \%$; Fisher's exact test, $P=0.011)$. Of the suicides in the case group, one involved hanging.

\section{Discussion}

A major increase in general hospital presentations was found for non-fatal hanging and self-strangulation, especially in recent years. This has paralleled the large increase in hanging as a method of suicide in the general population in the UK. ${ }^{1}$ The reasons for this are unclear. It is a major concern as prevention of hanging is extremely difficult outside of certain institutional settings such as psychiatric hospitals and prisons. ${ }^{1}$ The proportionate use of hanging and self-strangulation was similar to the pattern of use of these methods for suicide. Also, the male:female ratio in nonfatal hanging was 3:1, which is similar to that for suicide by hanging during the study period, ${ }^{1}$ whereas in the general selfharm population the ratio for the same catchment area is $0.8: 1{ }^{4,8}$ The excess of males who use hanging is in keeping with the general tendency for males to use more violent methods of suicide. ${ }^{9}$ Other important gender differences suggest that nonfatal hanging in females is associated with long-term psychiatric problems, personality disorder and previous self-harm, whereas males have little or no involvement with services.

The main factor distinguishing those using hanging from those using self-poisoning, other than gender difference, was higher suicidal intent. Many people using hanging are making 'suicide attempts', ${ }^{10}$ rather than engaging in self-harm for nonsuicidal reasons (e.g. demonstrating distress). The less frequent associations of alcohol consumption with hanging is in keeping with these acts involving higher suicidal intent ${ }^{6}$ and possibly lower impulsivity. The long-term risk of death from suicide appears to be greater in individuals using hanging for self-harm.

Limitations of the study include the lack of information on specific factors which may have influenced choice of method of self-harm (other than suicidal intent) and the extent of missing information. Strengths of the study include the long duration and the careful identification and characterisation of cases. ${ }^{4}$

People who use hanging and self-strangulation represent an important subgroup of patients who self-harm, who are presenting more frequently to the general hospital and who merit careful assessment and follow-up. Their characteristics and outcome suggest that further in-depth investigation could increase our understanding of the reasons why people are increasingly using hanging as a method of suicide.

Keith Hawton, DSC, Helen Bergen, PhD, Deborah Casey, BSC, Sue Simkin, BA, Centre for Suicide Research, University Department of Psychiatry, Warneford Hospital, Oxford, UK

Correspondence: Professor Keith Hawton, Centre for Suicide Research, University Department of Psychiatry, Warneford Hospital, Oxford OX3 7JX, UK. Email: keith.hawton@psych.ox.ac.uk

First received 5 Dec 2007, final revision 2 Jul 2008, accepted 10 Jul 2008

\section{Acknowledgements}

Funding from the Department of Health. K.H. is also supported by Oxfordshire and Buckinghamshire Mental Health NHS Foundation Trust. We thank Liz Bale, Anna Shepherd and staff at the Barnes Unit, John Radcliffe Hospital, for their assistance with data collection. The views expressed are solely those of the authors.

\section{References}

1 Gunnell D, Bennewith O, Hawton K, Simkin S, Kapur N. The epidemiology and prevention of suicide by hanging: a systematic review. Int J Epidemiol 2005; 34: 433-42.

2 Office for National Statistics. Mortality Statistics. Deaths Registered in 2006. Review of the Registrar General on Deaths in England and Wales, 2006. TSO (The Stationery Office), 2008.

3 Hawton K, Bergen H, Casey D, Simkin S, Palmer B, Cooper J, Kapur N Horrocks J, House A, Lilley R, Noble R, Owens D. Self-harm in England: a tale of three cities. Multicentre study of self-harm. Soc Psychiatry Psychiatr Epidemiol 2007; 42: 513-21.

4 Hawton K, Harriss L, Hall S, Simkin S, Bale E, Bond A. Deliberate self-harm in Oxford, 1990-2000: a time of change in patient characteristics. Psychol Med 2003; 33: 987-96.

5 Beck A, Schuyler D, Herman J. Development of suicidal intent scales. In The Prediction of Suicide (eds A Beck, H Resnik, DJ Lettieri): 45-56. Charles Press, 1974.

6 Harriss L, Hawton K, Zahl D. Value of measuring suicidal intent in the assessment of people attending hospital following self-poisoning or selfinjury. Br J Psychiatry 2005; 186: 60-6.

7 Hawton K, Zahl D, Weatherall R. Suicide following deliberate self-harm: long-term follow-up of patients who presented to a general hospital. Br J Psychiatry 2003; 182: 537-42.

8 Hawton K, Harriss L. The changing gender ratio in occurrence of deliberate self-harm across the life-cycle. Crisis 2008; 29: 4-10.

9 Denning D, Conwell Y, King D, Cox C. Method choice, intent and gender in completed suicide. Suicide Life Threat Behav 2000; 30: 282-8.

10 Douglas J, Cooper J, Amos T, Webb R, Guthrie E, Appleby L. 'Near-fatal' deliberate self-harm: characteristics, prevention and implications for the prevention of suicide. J Affect Disord 2004; 79: 263-8. 